\title{
The transmission of symbolic meaning in modern ceramic product design \\ Peng Fan
}

JiangXi Ceramic Fine Art Profession Academe,333000

Key words: modern ceramic products; symbolic meaning; transmission

\begin{abstract}
Ceramic products have a long history, in the process of historical development, with its unique charm to attract millions of people. And it is also one of the composition of culture. It is reflected in its own and reflected in the various symbols in the design process of ceramics. This paper gives a brief introduction to the transmission of symbolic meaning in the design of modern ceramic products.
\end{abstract}

\section{Introduction}

As one of the daily household items, ceramic products in addition to the necessary functions, also have to take into account the aesthetic.Its own dual attributes are embodied in both material and cultural functions.In the design process of modern ceramics, we should take into account the combination of traditional and contemporary aesthetic requirements, combine the requirements of the present to the aesthetic, in order to meet the needs of different groups of people, reflect its higher value.

\section{The history and development style of ceramics}

Ceramics are the totals of pottery and porcelain, and the invention of pottery is probably in the Neolithic Age. Ceramic materials are several different compounds, Common clay has clay, kaolin and so on. Ceramic materials are usually poor in plasticity, but have a higher hardness. Ceramics used in raw materials at different temperatures can be fired into different shapes of utensils, it played an important role in life. At present, the daily function of life gradually fade but its application in the scope of scientific and technological creativity in the gradual expansion.

There is no textual research on the pottery making technology in ancient times, in pre-Qin period, because bronze can only be aristocratic all, ceramics in the civil have further development. And the classification is also wide, daily, construction, sacrifice and so on. Ceramics has shown a situation of South cyan North White in the history of China. In the three kingdoms and Jin period, Jiangnan area of the ceramic industry is developing very rapidly. White porcelain appeared in the Northern and Southern Dynasties, the impact on future generations far-reaching. Ceramic mature dynasty appeared in the Tang Dynasty, the technology has been very mature. After the Song Dynasty is its heyday, official kilns and folk kilns coexist. In the Yuan Dynasty appeared more famous varieties, Qinghua. After Qing Dynasty the ceramic technology had a further development, in order to know the enamel, purple sand and so on. The development of Chinese national industry has been impacted, and the development of ceramic industry has gradually entered a recession. After the founding of new China, the ceramic industry has ushered in a new development.

Ceramics is not only in our country reputation, but also exported to overseas. English word in China, one of which means porcelain. After a long history of development, from the emergence to the development, to the glorious decline, rejuvenated. Chinese ceramics contains a rich cultural connotation in which.

The initial role of ceramic products is to meet people's daily life needs, then integrate cultural elements into them in the development process, ceramic products reflect the perfect integration of technology and art. In the process of ceramic development, the process of evolution has the intersection of different process technology. From the early abstract design to the heavy decoration, and then to the no decoration. From the daily necessities to the craft, has gone through the process 
of transition from functional to practical, after experiencing the period of emphasising on materials and functions, transferred attention to the material stage. With the changes of people's aesthetic, the shape of ceramic products are also undergoing a corresponding change, this change also reflects the unity of technology and technice.

\section{Design symbols in modern ceramic products}

Modern ceramic product design features can be simply summed up as a few points, first has a certain organizational structure, the second is the symbol of the material, the third is culture. From the composition of view, can be composed of artificial materials by the entity, and can also be a natural object in the environment.

Symbol as the carrier of information, which itself is a kind of information. Different symbols and integration into ceramic products will have different meanings. Ancient ceramic products have different symbols on their surfaces, they can also be called different elements. The combination of elements in the development process will have a certain cultural significance. Modern ceramic design is different from the traditional characteristics. The symbols in the ceramic design can be divided into indicative, symbolic and graphic. The image and indicative are expressed in graphical and color forms. Symbolic is the embodiment of emotions, thought and concept. Popular is the meaning of the product to express. Because the ceramic can be flexibly combined in shape, color and texture, which formed the symbol is very rich. Ceramic symbols through the human sensory organs to stimulate the people accepted, and through the brain's thinking, perception and others to be understood and stored. The designer in the process of creation is to integrate different symbols, through the collocation of different elements, and the cultural meaning of different elements, the psychological activities of the human body, integrate emotion and thought into the creation, which to create a modern ceramic products. The elements include shape, material, color, etc. Some elements can be equated with human emotions, based on this can create products bearing material and spiritual and cultural value ${ }^{[1]}$.

\section{Transmission of symbolic meaning}

The symbol is the carrier of some information, the effectiveness of information in the process of communication lies in whether the recipients of different information can accurately understand the meaning of the symbol and the hidden information. Most of the ancient ceramic technology is based on experience, not consciously even unconsciously fuses emotional elements. And modern ceramic production has more specific reference. The application of symbols should take into account many aspects, personal preferences, consumer psychology, social culture. The symbol in the design process involves aesthetics, also involves the category of psychological knowledge, such as color will have a role in human psychology.

Considering many aspects of modern ceramic production symbol design, the most important is to meet the needs of consumers. The physiological and psychological needs of the deeper meaning attributed a pleasant feeling. The symbol can be considered as a visual language, its physical existence is based on certain symbolic entities, passing information to consumers through symbols. Information includes the functional requirements of life, and also includes the cultural and spiritual aspects of it.

In the expression of symbolic design, the connotation of symbolic design is formed by the combination of different elements of ceramic products. Including the different of material, the different of line and surface, transition, modeling contrast, etc. The variety of modern ceramics is much more than the traditional manufacturing process. Different kinds have their own language, and from different angles to cut into the theme, thus reflect the characteristics of different products, and finally reflect the connotation. The symbol design should meet the requirements of two aspects, one is the requirements of product design, and the other is the requirements of consumers. Symbolic design is not a simple collocation of different symbols elements, but to make corresponding thinking of its connotation, avoid the symbolic accumulation in meaning expression, language is 
empty ${ }^{[2]}$.

The emotional expression of the symbol. The expression of emotional meaning can be considered from the subject, decoration, component and texture of ceramics. First of all, the subject, the designer will through a certain form of artistic expression of the subject, as far as possible put the emotional elements into it. Such as simple, gorgeous, dignified, different forms of people will produce corresponding association, so as to produce aesthetic taste. In addition, in terms of the components, ceramics' shape have no significant changes, but in terms of components, it shows a subtle difference. The ceramic components usually include the hand, cover, button, mooring, flow, etc. The lid can be regarded as a necessary component of ceramics. The most basic should meet the practical function. On this basis, designers give different styles and colors. The use of form and color is actually expressed in the design of aesthetic and emotional experience. In the decorative pattern, can be divided into emotional expression and posture, expression of expression. In the early period, the decoration of ceramics was mainly abstract abstract expression, in the course of the development process become rich and varied. In addition, in decoration, on the basis of traditional pay more attention to morphological changes and as a way of emotional expression. In the color expression, pay more attention to different colors of the people's psychological activities and the relationship between color and people's psychology. For example, use red to express happy and use flowers to express the pursuit of good things ${ }^{[3]}$.

The material symbol design expression. The texture of the material can be divided into two aspects, the basic material of different texture, the changing parts material. Ceramic and porcelain materials reflect the product texture is different. The combination of different materials can make the material more prominent. For example, when the tea set in design, matching white porcelain with wood materials, body has no handle, but has outsourced wood chips. Avoiding hot also increase the effect of insulation. The storage tank lid in the tea set is made of wood to keep the lid. The whole gives a simple feeling. The lid of the storage tank in the tea is made of wood to preserve the tea. The whole gives a quaint feeling.

\section{Concluding remarks}

In general, the transmission of symbolic meaning in modern ceramic design is based on different surface forms and different elements. Ceramics in the production process should pay attention to its own, and take into account the aesthetic and symbols to convey the information, so as to better design.

\section{Reference:}

[1] Peng Xiao. A brief discussion on the symbolization trend of modern ceramic product design [J]. Works of art, 2015 (08).

[2] Sun Kankan. Research on the emotional expression of daily ceramic design [J]. ShenYang Ligong University, 2011 (3).

[3] Huang Yun. Research on "Tao Yuanming" brand of tea packaging design under the background of cultural creative industry[D]. Hunan Normal University, 2015 (5). 